\title{
Analysis of Cooling Curves of Nodular Cast Iron
}

\author{
Marianna Bartošová*, Alena Pribulová, Štefan Eperješi, Peter Futáš \\ Technical University of Kosice, Department of Metallurgy and Foundry, Faculty of Materials, Metallurgy and Recycling, Letna 9, 04200 Kosice, \\ Slovakia \\ ${ }^{*} e$-mail: marianna.bartosova@tuke.sk
}

Received: 10 October 2017/Accepted: 11 January 2018/Published online: 30 March 2018

This article is published with open access at AGH University of Science and Technology

\begin{abstract}
The solidification of cast iron is a complex process with characterized entrance and marginal conditions. Thermal analysis is one of the processes that allows us to observe the solidification of alloys. There is a possibility of gaining information about the melted cast iron quality and predicting the final properties of the cast by evaluating the scanned cooling curves by solidification (stable and metastable system). This article deals with the study and analysis of cooling curves taken from production conditions of a foundry during ductile cast iron production. The aim is to discover the reproduction and reliability of the thermal analysis results of cast iron. The study of the progress of the cooling curves and their first derivation to follow the reactions of the curves to changing factors in the production process.
\end{abstract}

\section{Keywords:}

cooling curve, nodular cast iron, eutectic transformation, thermal analysis, metallurgical quality

\section{INTRODUCTION}

Thermal analysis, based on evaluation of cooling curves of samples of molten metal cooling in a testing crucible, is not something new in foundry. Nevertheless, it can be stated, that not all possibilities, that analysis can provide are being exploited. Nowadays, the devices for thermal analysis are based on top equipment and software. In addition to the characteristics of cooling curves and other qualitative indicators, it is possible to use the devices for collecting measurement results from different laboratories (results of chemical analysis, mechanical properties, structural analysis, etc.) and also determining a statistic evaluation of the collected data. The known fact is, that it is necessary to make the production process as stable as possible to obtain reliable results by thermal analysis. It is known and used in the praxis; that, via thermal analysis, it is possible to quickly establish the basic chemical composition (\%C, \%Si, Se). However, from cooling curves and their characteristics, it is possible to obtain information about the crystallization and graphitization processes during the solidifying and cooling of the sample of cast iron, in other words, it is possible to obtain information about the metallurgical quality of molten cast iron before casting. The current literature is greatly focusing on this application. This application can provide valuable knowledge, and important manufacturers of devices for thermal analysis are equipping their analyzers with software that can evaluate the metallurgical state of molten metal and also predict the final structure and mechanical properties of cast iron after cooling [1-3].

On the other hand, the use of a thermal analysis of cast iron is very problematic under practical conditions.
In published papers [4-6], it was stated that it is not possible to make solid conclusions using the results of thermal analysis of cast iron under different practical conditions. As mentioned before, one of the main reasons for this problem is; that the process stability is not sufficient in the tested foundries; therefore, a lot of influencing factors cause unreliability in the obtained results [7].

\section{EXPERIMENTAL PROCEDURES}

All measurements were realized by ductile cast iron production (EN-GJS-500-7) in the operating conditions of a foundry. The initial melt was prepared in an 8-ton middle frequency induction furnace with acid brickwork. The composition of the used charge was: SOREL pig iron, hematite, and steel scrap. After preheating to $1500^{\circ} \mathrm{C}$, the molten metal was treated by the Tundisch-Cover method (into a 2 t ladle).

Foundry alloy FeSiMg (with $5 \%$ of $\mathrm{Mg}$ ) in a quantity of $3 \mathrm{~kg}$ (it is $1.9-2 \%$ of the weight of the molten metal) was used as a modifier. The treated molten metal was inoculated by pouring it into a foundry ladle according to technological rules. Three hundred $\mathrm{kg}$ of molten metal was left in the treated ladle because of the experiments. From this, $20 \mathrm{~kg}$ was used for the experiment without inoculation (melting Nos. 11, 21, 31, ..., 81 - see Tab. 1); next, $20 \mathrm{~kg}$ of molten metal was inoculated with a smaller quantity of inoculation (sampling of cast iron Nos. 12, 22, $32, . ., 82$ ). Finally, $20 \mathrm{~kg}$ of molten metal was inoculated with a higher quantity of inoculant (Nos. 33, 43, 53, ..., 83). The metallurgical conditions of the molten metal were changed by the quantity and quality of the used inoculants. 
An overview of the metallurgical treatment of the cast iron from eight observed molds is shown in Table 1.

Table 2 shows the chemical composition of tested cast irons realized by spectral analysis. Eutectic degree Se shows that all tested cast irons were hypereutectic. The TERMOCARB apparatus assembled at the Department of Foundry in Miscolc University in Hungary was used for the analysis [8].

Shell pots "Quick - cup" without telur were used, enabling us to achieve grey solidification. The collected variations of temperature by the cooling of samples were registered via the ADAM converter with GENIE software. No software was used for reading the characteristic temperatures on the cooling curves. The results of the thermal analysis are shown in Table 3.

Three testing Y-blocks for testing the mechanical properties and metallographic analysis were poured from each melt; the first after modification treatment, the second after inoculation with a smaller quantity of the inoculating agent, and the third after larger part of the inoculation agent.

Table 1

Used quantity and kinds of modification and inoculation additives by treatment of tested cast irons

\begin{tabular}{|c|c|c|}
\hline Number of melt & Modification & Inoculation \\
\hline 11 & $38 \mathrm{~kg}$ FeSiMg & - \\
\hline 12 & $+1 \mathrm{~kg}$ CeMM & $0.2 \%$ Barinoc \\
\hline 21 & \multirow{2}{*}{38 kg FeSiMg } & - \\
\hline 22 & & $0.2 \%$ Barinoc \\
\hline 31 & \multirow{3}{*}{38 kg FeSiMg } & - \\
\hline 32 & & $0.2 \%$ Barinoc \\
\hline 33 & & $0.3 \%$ Barinoc \\
\hline 41 & \multirow{3}{*}{38 kg FeSiMg } & - \\
\hline 42 & & $0.1 \%$ FeSiCe MM40 \\
\hline 43 & & $0.3 \% \mathrm{FeSiCe}$ MM40 \\
\hline 51 & \multirow{3}{*}{38 kg FeSiMg } & - \\
\hline 52 & & $0.2 \%$ Superseed \\
\hline 53 & & $0.3 \%$ Superseed \\
\hline 61 & \multirow{3}{*}{38 kg FeSiMg } & - \\
\hline 62 & & $0.2 \%$ Barinoc \\
\hline 63 & & $0.4 \%$ Barinoc \\
\hline 71 & \multirow{3}{*}{$38 \mathrm{~kg} \mathrm{FeSiMg}$} & - \\
\hline 72 & & $0.2 \%$ Barinoc $+0.1 \% \mathrm{FeSiCeMM}$ \\
\hline 73 & & $0.4 \%$ Barinoc $+0.1 \% \mathrm{FeSiCeMM}$ \\
\hline 81 & \multirow{3}{*}{38 kg FeSiMg } & - \\
\hline 82 & & $0.2 \%$ Foundrysil $+0.1 \%$ FeSiCeMM \\
\hline 83 & & $0.4 \%$ Foundrysil $+0.1 \% \mathrm{FeSiCeMM}$ \\
\hline
\end{tabular}

Table 2

Chemical composition of tested cast irons

\begin{tabular}{|c|c|c|c|c|c|c|c|}
\hline $\begin{array}{l}\text { Sample } \\
\text { number }\end{array}$ & $\% \mathrm{C}$ & $\% \mathbf{S i}$ & $\% \mathrm{Mn}$ & $\% S$ & $\% \mathrm{P}$ & $\% \mathrm{Mg}$ & Se \\
\hline 11 & 3.84 & 2.35 & 0.39 & 0.020 & 0.056 & 0.089 & 1.0940 \\
\hline 12 & 3.70 & 2.48 & 0.43 & 0.025 & 0.054 & 0.087 & 1.0708 \\
\hline 21 & 3.66 & 2.33 & 0.41 & 0.016 & 0.050 & 0.079 & 1.0437 \\
\hline 22 & 3.82 & 2.28 & 0.38 & 0.018 & 0.048 & 0.071 & 1.0817 \\
\hline 31 & 3.98 & 2.21 & 0.36 & 0.021 & 0.051 & 0.086 & 1.1223 \\
\hline 32 & 3.70 & 2.24 & 0.36 & 0.017 & 0.044 & 0.075 & 1.0456 \\
\hline 33 & 4.12 & 2.09 & 0.35 & 0.014 & 0.049 & 0.083 & 1.1486 \\
\hline 41 & 3.74 & 2.41 & 0.37 & 0.013 & 0.047 & 0.067 & 1.0707 \\
\hline 42 & 3.80 & 2.50 & 0.35 & 0.019 & 0.045 & 0.059 & 1.0962 \\
\hline 43 & 3.81 & 2.49 & 0.35 & 0.015 & 0.046 & 0.063 & 1.1005 \\
\hline 51 & 3.74 & 2.36 & 0.38 & 0.016 & 0.048 & 0.071 & 1.0663 \\
\hline 52 & 3.73 & 2.52 & 0.39 & 0.020 & 0.046 & 0.069 & 1.0779 \\
\hline 53 & 3.82 & 2.48 & 0.41 & 0.021 & 0.043 & 0.072 & 1.0918 \\
\hline 61 & 3.79 & 2.41 & 0.39 & 0.023 & 0.048 & 0.078 & 1.0868 \\
\hline 62 & 3.85 & 2.54 & 0.40 & 0.028 & 0.045 & 0.069 & 1.1197 \\
\hline 63 & 3.68 & 2.60 & 0.39 & 0.024 & 0.047 & 0.061 & 1.0768 \\
\hline 71 & 3.75 & 2.39 & 0.38 & 0.018 & 0.046 & 0.065 & 1.0751 \\
\hline 72 & 3.72 & 2.59 & 0.38 & 0.014 & 0.045 & 0.065 & 1.0871 \\
\hline 73 & 3.83 & 2.75 & 0.37 & 0.013 & 0.041 & 0.062 & 1.1366 \\
\hline 81 & 3.79 & 2.47 & 0.37 & 0.019 & 0.045 & 0.080 & 1.0948 \\
\hline 82 & 3.85 & 2.68 & 0.38 & 0.020 & 0.045 & 0.073 & 1.1351 \\
\hline 83 & 4.11 & 3.02 & 0.37 & 0.022 & 0.041 & 0.091 & 1.2530 \\
\hline
\end{tabular}

Table 3

Results of the thermal analysis (Possibilities of evaluating field of liquidus on the cooling curve were not the same in all cases. Field of liquidus is characterized by either only $T L$ or minimal and maximal $T L$ )

\begin{tabular}{|c|c|c|c|c|c|c|}
\hline $\begin{array}{l}\text { Sample } \\
\text { number }\end{array}$ & $\begin{array}{l}T L, \\
{ }^{\circ} \mathrm{C}\end{array}$ & $\begin{array}{l}T L_{\min }, \\
{ }^{\circ} \mathrm{C}\end{array}$ & $\begin{array}{l}T L_{\max ^{\prime}} \\
{ }^{\circ} \mathrm{C}\end{array}$ & $\begin{array}{l}T E_{\min }, \\
{ }^{\circ} \mathrm{C}\end{array}$ & $\begin{array}{c}T E_{\max ^{\prime}} \\
{ }^{\circ} \mathrm{C}\end{array}$ & $\begin{array}{l}\mathrm{TS}, \\
{ }^{\circ} \mathrm{C}\end{array}$ \\
\hline 11 & - & 1144.5 & 1146.3 & 1131.6 & 1134.3 & 1079.9 \\
\hline 12 & - & 1148.4 & 1149.5 & 1145.3 & 1146.6 & 1073.1 \\
\hline 21 & - & 1131.7 & 1132.5 & 1132.5 & 1137.5 & 935.3 \\
\hline 22 & - & 1138.2 & 1139.2 & 1135.6 & 1137.6 & 1080.9 \\
\hline 31 & - & 1130.8 & 1132.5 & 1132.5 & 1137.9 & 1090.2 \\
\hline 32 & - & 1137.4 & 1139.1 & 1134.7 & 1138.3 & 1091.5 \\
\hline 33 & 1150.8 & - & - & 1145.8 & 1146.4 & 1091.8 \\
\hline 41 & - & 1138.9 & 1139.3 & 1135.6 & 1137.1 & 1075.0 \\
\hline 42 & - & 1139.1 & 1139.3 & 1136.6 & 1139.2 & 1097.1 \\
\hline 43 & 1156.2 & - & - & 1148.4 & 1150.6 & 1106.7 \\
\hline 51 & 1163.6 & - & - & 1131.2 & 1138.7 & 1094.0 \\
\hline 52 & 1151.8 & - & - & 1147.7 & 1149.6 & 1099.9 \\
\hline 53 & - & 1143.3 & 1143.5 & 1142.8 & 1143.1 & 1083.2 \\
\hline 61 & - & 1128.8 & 1130.0 & 1128.3 & 1133.6 & 1095.5 \\
\hline 62 & - & 1153.0 & 1153.1 & 1147.0 & 1148.3 & 1094.6 \\
\hline 63 & 1159.5 & - & - & 1148.3 & 1150.4 & 1096.5 \\
\hline 71 & - & 1131.9 & 1133.1 & 1131.2 & 1135.1 & 1058.3 \\
\hline 72 & - & 1146.0 & 1146.9 & 1144.8 & 1145.3 & 1093.9 \\
\hline 73 & 1160.1 & - & - & 1147.3 & 1149.2 & 1093.4 \\
\hline 81 & - & 1141.0 & 1141.6 & 1135.3 & 1136.1 & 1089.9 \\
\hline 82 & 1155.0 & - & - & 1146.2 & 1147.2 & 1093.1 \\
\hline 83 & 1174.1 & - & - & 1148.4 & 1150.7 & 1099.8 \\
\hline
\end{tabular}




\section{EVALUATION OF COOLING CURVES SHAPES}

In this contribution, the shape of the cooling curves of nodular cast iron with different kinds and quantities of inoculants were compared (Tab. 1).

Because the observed nodular cast irons were eutectic and hypereutectic, their evaluation was more complicated. For highlight of changes, that were not on the simple cooling curve remarkable the first derivation was made (Fig. 1).

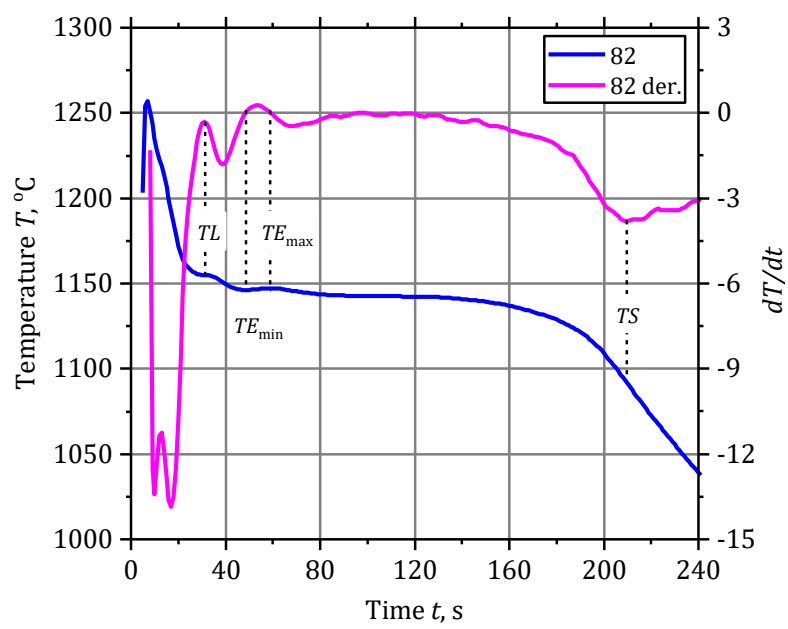

Fig. 1. Cooling curve and their first derivation (Melt 82)

The first derivation of the cooling curve shows the speed of sample cooling. The speed is changing with loose latent heat of solidification by the precipitation of phases. It is possible to read the next characteristic temperatures from the cooling curve: $T L, T E_{\text {min }}, T E_{\text {max }}, T S$. The liquidus temperature presents the beginning of solidification depending on eutectic index Se, and after [9], it should be within a temperature range of $1140-1155^{\circ} \mathrm{C} . T E_{\min }$ is the minimal eutectic temperature that is connected with the occurrence of cementite in the structure of the cast iron. Maximum eutectic temperature $T E_{\max }$ is connected with precipitation of the graphite. TS is the temperature of the solidus by which the solidification is finished. The difference between $T E_{\max }$ a $T E_{\min }$ is recalescence. The value of the recalescence is related to the expansion of the graphite volume.

The cooling curves of the cast irons and their first derivations are shown in Figures 2-4. All of these cast irons were treated by the same method $(38 \mathrm{~kg} \mathrm{FeSiMg}$ and $0.2 \%$ Barinoc).

The differences of the shape of the cooling curves and their first derivations in the whole solidification interval are evident from the graphics. The eutectic area of the cooling curves (Melts 22 and 32) is under a temperature of $1140^{\circ} \mathrm{C}$ (contrary to Melt 62), but the shape of the cooling curve of Melt 22 and the course of the first derivation are closer to the shape of the cooling curve of Melt 62 . In spite of this, the results of the structural analysis (number of graphite nodules, part of pearlite, and ferrite) and mechanical properties indicate that Melts 22 and 32 possess nearly the same quality. The differentness of the curve of the sample from Melt 32 (Fig. 3.) can be caused by the low casting temperature of this sample.

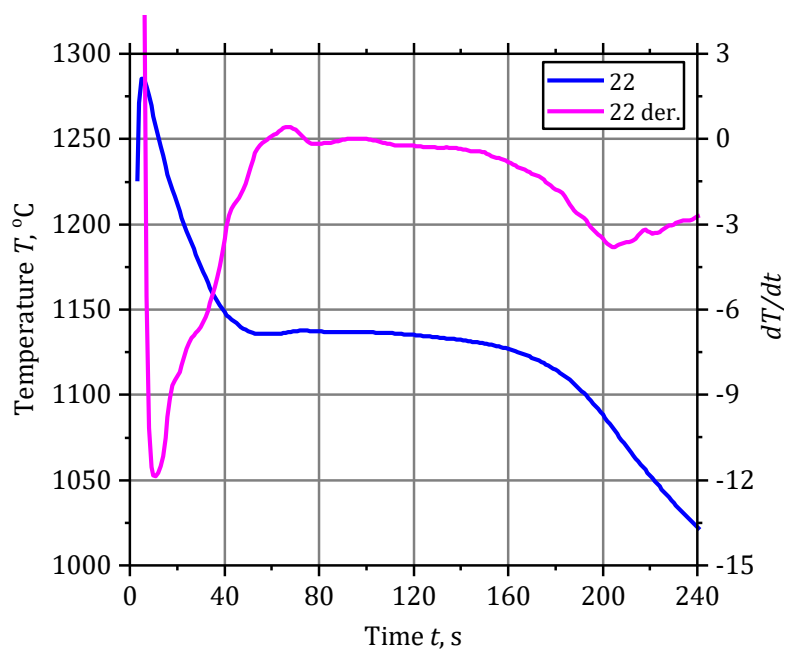

Fig. 2. Cooling curve of Melt 22

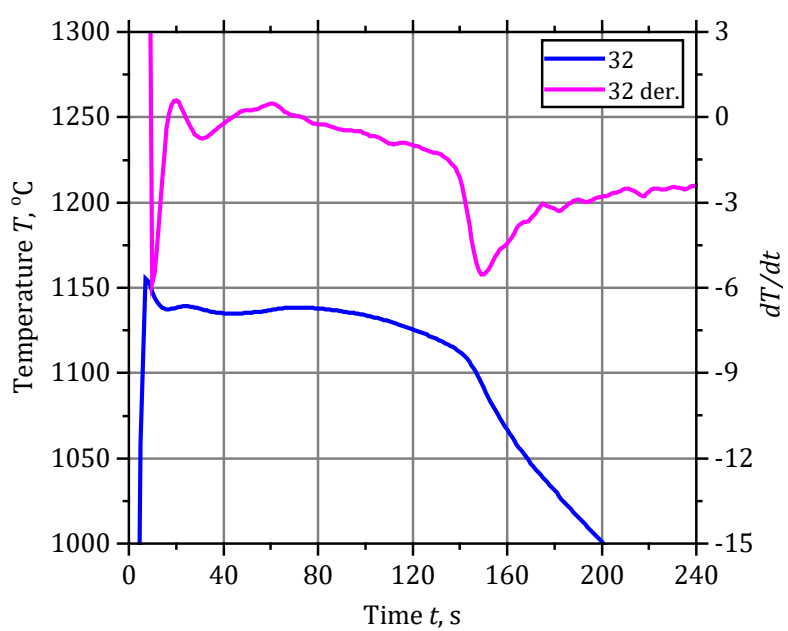

Fig. 3. Cooling curve of Melt 32

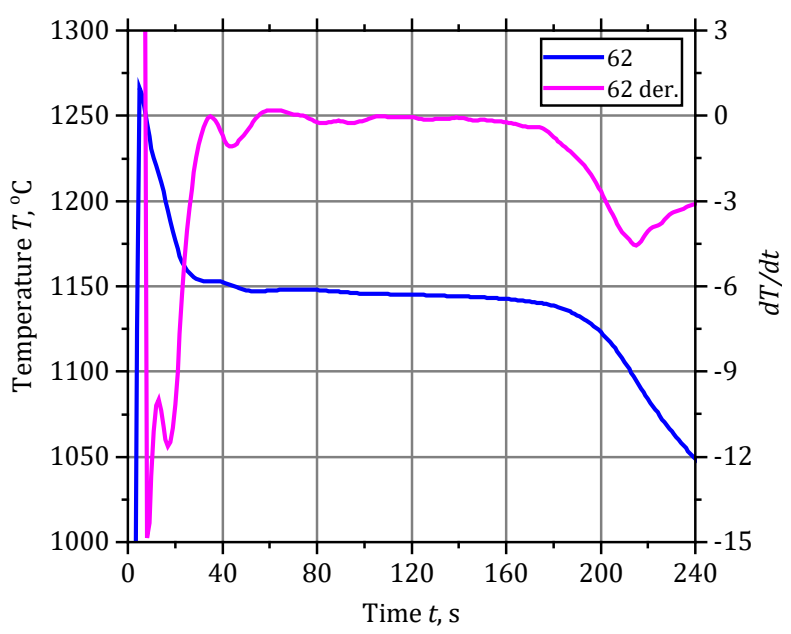

Fig. 4. Cooling curve of Melt 62 
In the sample of Melt 62, the eutectic transformation was under a temperature of $1140^{\circ} \mathrm{C}$, which manifested in a higher number of graphite globules (nearly double) as compared with Samples 22 and 32. All three samples filled the mechanical properties that were given by the standard.

In Figures 5 and 6, the cooling curves of the cast irons inoculated with the same inoculant (Barinoc) but with different quantities $(0.2$ and $0.4 \%)$ are presented.

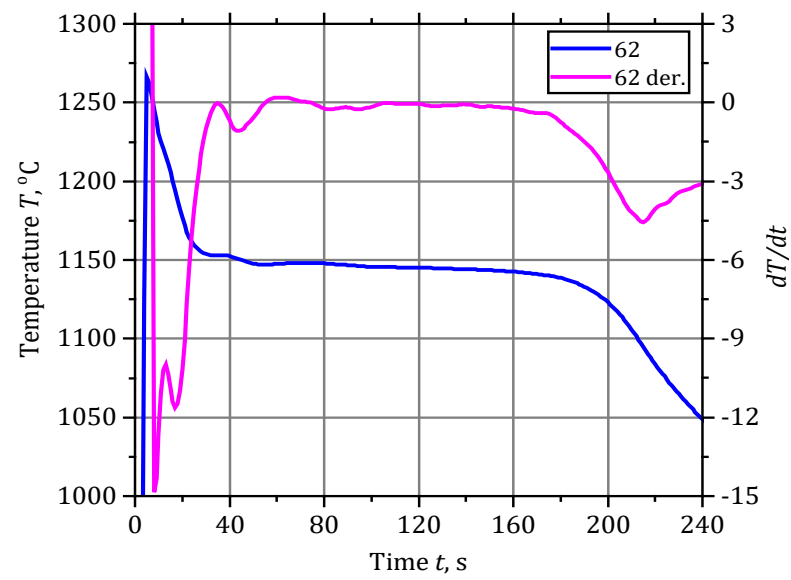

Fig. 5. Cooling curve of Melt 62

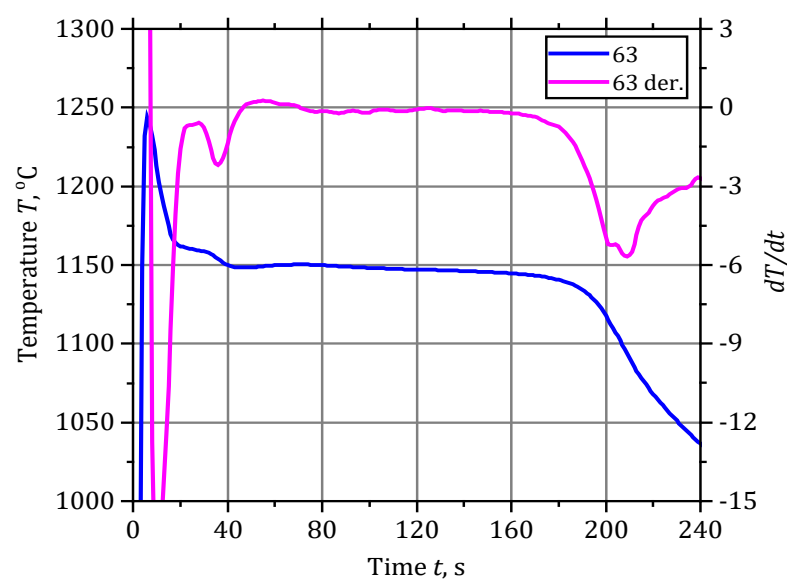

Fig. 6. Cooling curve of Melt 63

By a comparison of the shape of the cooling curves, marked differences were not observed for Melts 62 and 63. It is possible to state that a greater quantity of inoculants does not bring evident changes in the cooling curve shape ( $T L$ is markedly higher in Melt 62 , but the eutectic temperatures increased only moderately). Alteration of the inoculant quantity only partially influences the resulting properties of the cast iron. By adding a greater amount of inoculant, the number of graphite nodules increased two-fold, but the mechanical properties changed only a little. A similar situation was observed with a similar quantity of the other used inoculant.

\section{CONCLUSIONS}

By an observation of cooling curve shape and the shape of its first derivation, the following points were determined:

- by using the same kind of inoculant and one basic melt (Melt 62 and 63), increasing the inoculant quantity did not reflect stronger on the curve shape; a stronger difference was only in the liquidus temperature, but the eutectic temperatures did not rise so markedly,

- it is possible to suppose that the dissimilarity balanced cooling curve shape was caused by the melt properties before inoculation and condition management of the melt, because the cooling curves were different with the same kind and quantity of inoculant,

- on the basis of this contribution and works dedicated to the dependencies between the characteristic temperatures of cooling curves and resulting cast iron properties, it is possible to note that the characteristic temperatures from the cooling curves respond more to the modification of the metallurgical state of melt after inoculation,

- the number of graphite globules in the cast iron structure reacted the most markedly depending on the kind and quantity of inoculator, and it corresponded with changes on the cooling curve specifically with the values of the eutectic temperatures.

\section{Acknowledgments}

This work was supported by the Scientific Grant Agency of The Ministry of Education of the Slovak republic No. VEGA1/0073/17 and VEGA 1/0703/16.

\section{REFERENCES}

[1] Stefanescu D.M. (2015). Thermal Analysis - Theory and Applications in Metalcasting. International Journal of Metalcasting, 9 (1), 7-22.

[2] Diószegi A. \& Svensson I.L. (2005). On the problems of thermal analysis of solidification. Journal of Materials Science and Engineering A, 413-414, 474-479.

[3] Gedeonová Z. \& Jelč I. (2000). Metalurgia liatin. Košice: HF TU $v$ Košiciach.

[4] Bartošová M., Stríž T. \& Eperješi Š. (2015). Skúsenosti zistené pri hodnotení kvality LGG pomocou termickej analýzy. Quo vadis zlievarenstvo 2015: 14-16.10.2015, Sninské rybníky, Košice: Technical University in Košice, 12-14.

[5] Bartošová M. \& Pribulová A. (2005). Experiences with commercial thermoanalysator used in the foundry. Acta Metallurgica Slovaca, 11(3), 29-32. doi: 10.12776/ams.v20il.273

[6] Bartošová M. \& Pribulová A. (2006). The study of cooling curves of nodular cast iron. $7^{\text {th }}$ International Foundrymen Conference: Advanced foundry materials and technologies: 12-14.06.2006, Opatija. Zagreb: University of Zagreb, 5-9.

[7] Li Y. \& Wang 0. (2005). Intelligent evaluation of melt iron quality by pattern recognition of thermal analysis cooling curves. Journal of Materials Processing Technology, 161, 430-434.

[8] Hajdu A. (2002). Diploma thesis. Őntészeti Tanszék, Metallurgiai intészet, Miskolci Egyetem.

[9] Santorini F. \& Powell C. (2011). Gründe für die Anwendung der Thermischen Analyse bei der Produktion von Grau- und Sphäroguss. Giesserei-Rundschau, 58 (11/12), 273-277. 